\title{
Spontaneous Hemoperitoneum Masquerading Placental Abruption: A Case Report
}

\author{
Subedi S, Banerjee B \\ Department of Obstetrics and Gynaecology, Nobel Medical College and Teaching Hospital
}

\begin{abstract}
Hemoperitoneum during pregnancy is a rare but potentially life threatening condition to both mother and fetus. Spontaneous hemoperitoneum may develop from rupture of various abdominal or pelvic viscera like spleen, pancreas and also uterus from the uterine ovarian vessels and rarely from pelvic endometrial implants. It mimics placental abruption having similar clinical presentation like acute abdominal pain, peritonitis, shock and fetal distress or fetal death. We present a case of spontaneous rupture of superficial uterine vessels in third trimester of pregnancy with an objective to share our experience in managing this rare emergency condition having diagnostic dilemmas.
\end{abstract}

Keywords: Placental abruption, rupture of uterine vessel, spontaneous hemoperitoneum

\section{INTRODUCTION}

Hemoperitoneum during pregnancy is rare but potentially life threatening to both mother and fetus. Spontaneous hemoperitoneum may develop from rupture of various abdominal or pelvic viscera like spleen pancreas and also uterus from the uterine ovarian vessels and rarely from pelvic endometrial implants. It mimics placental abruption having similar clinical presentation like acute abdominal pain, peritonitis, shock and fetal distress or death. Timely surgical intervention with appropriate volume replacement provides the best outcome.

We present a case of spontaneous rupture of superficial uterine vessels in third trimester of pregnancy and its objective is to share our experience in managing this emergency condition though rare in pregnancy and all the diagnostic dilemmas we had during this case management.

\section{CASE}

A 23 year unbooked primigravida, at 27 weeks 5 days period of gestation presented in Nobel Medical College Teaching Hospital on 15th April 2012 with acute abdomen for 12 hours without any history of trauma and bleeding.

\section{CORRESPONDENCE}

Dr. Shanti Sunuwar Subedi, MD

Asso Professor, Department of Obstetrics and Gynaecology Nobel Medical College and Teaching Hospital, Biratnagar Phone: 9852027375

Email: drshantisubedi@yahoo.com
On examination, she was not pale, blood pressure was $100 / 60 \mathrm{mmHg}$, pulse rate was $74 / \mathrm{min}$, abdomen was tense and tender (Fig 1) with regular FHS of 130/min. Patient was admitted and administered IV antibiotics and analgesics. Ultrasound (USG) on the same day revealed normal obstetric scan with small uterine myoma of $3 \mathrm{~cm}$ in the anterior myometrium.

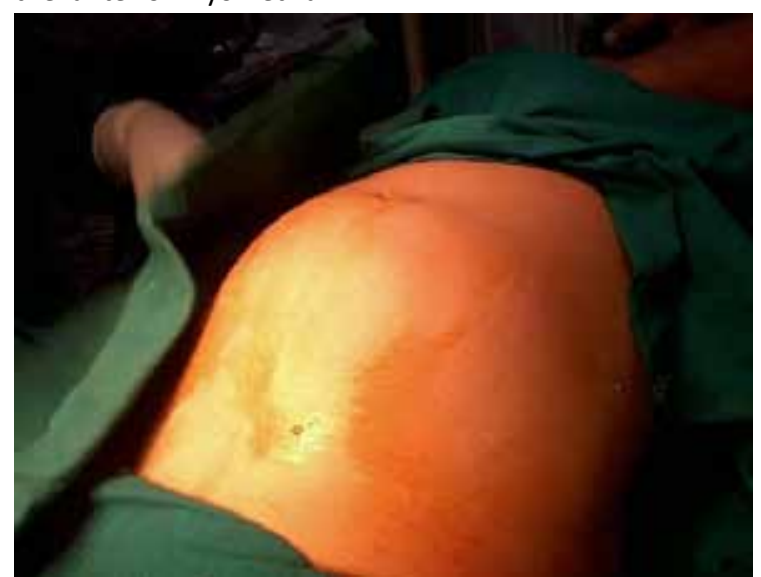

Figure 1. Primigravida at $\mathbf{2 7}$ wks period of gestation with acute abdomen 
With the suspicion of red degeneration of myoma, conservative management was done, until the haemoglobin $(\mathrm{Hb})$ was noticed to fall down from $12 \mathrm{gm} \%$ to $7.2 \mathrm{gm} \%$ the next day and repeat USG showed a picture of frank hemoperitoneum. She was transfused with 2 units of 0 positive blood and emergency exploratory laparotomy was done on 3rd day of admission with clinical impression of Abruptio placenta.

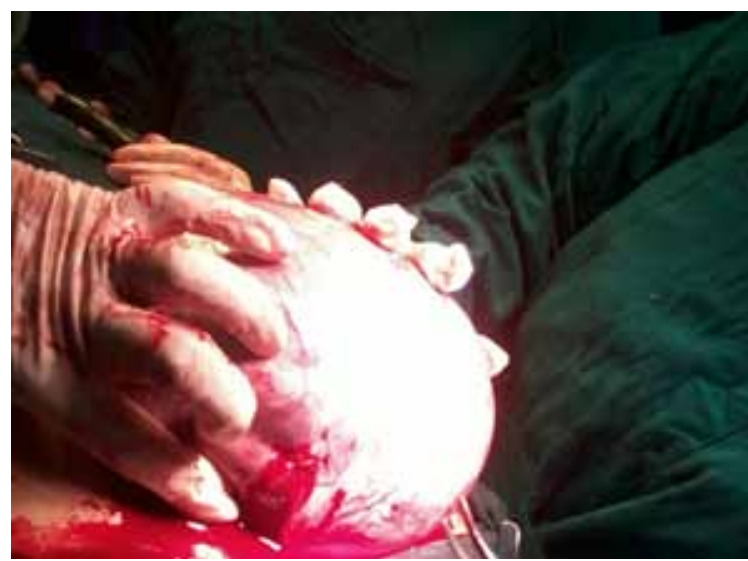

Figure 2. Veinous prominence and vascularity seen in the posterior surface of the uterus

On opening the abdomen there was around 1.5 litres of blood with clots of $500 \mathrm{gm}$, which after being cleared showed profusely bleeding vessel from posterior uterine wall (Fig 2). When the preliminary attempt at securing the bleeding vessel was not possible, anterior hysterotomy was performed with the delivery of $800 \mathrm{gm}$ female baby with low Apgar score who died after few hours of life. Additional 5units of blood was transfused thereafter. Her postoperative recovery was good and she was finally discharged on ninth postoperative day.

\section{REFERENCES}

1. Koifman A, Weintraub AY, Segal D. Idiopathic spontaneous hemoperitoneum during pregnancy. Arch Gynecol Obstet. 2007;276(3):269-70.

2. Hashimoto K, Tabata C, Ueno Y, Fukuda H, Shimoya K, Murata Y Spontaneous rupture of uterine surface varicose veins in pregnancy: a case report. J Reprod Med. 2006;51(9):722-4.

\section{COMMENT}

Spontaneous hemoperitoneum during pregnancy is rare and the associated morbidity and mortality rates are approximately $49 \%$. The pre-operative diagnosis is usually placental abruption in majority of cases but this has not been the case always. ${ }^{1-5}$

On opening abdomen, source of bleeding vessel may not always be visible even after thorough exploration in the case of hemoperitoneum. ${ }^{1}$ However, rupture of ovarian venous plexus in later half of pregnancies contributing to hemoperitoneum have come to knowledge through two reported cases in this connection. It is said that rupture of utero-ovarian plexus usually occur in the third trimester but can occur in all trimesters besides puerperium.4 Primary cause for this is still obscure but physiological increase in blood flow to the utero-ovarian vessels during pregnancy imparted by dilatation of vessel may be reasoned to undergo spontaneous rupture.

Uterine surface varicose vein have also been involved in rupture and veins over the posterior wall of the uterus like our case has been mentioned. 2,3,5 One such case that resembles our case, where superficial vein on the posterior uterine wall that got ruptured at 32 weeks of gestation but where both baby and mother were saved by timely caesarean section and volume replacement is worthy of mention here. ${ }^{5}$ There have been few cases culminating in hysterectomy, like that of ours. ${ }^{2}$

\section{CONCLUSIONS}

In conclusion one must always think of the rare possibility of rupture of venous supply in and around uterus before the lab findings of drastic fall in hematocrit in cases of acute abdomen in pregnancy as with this case.

3. Nahar K, Begum H, Khatun M. Spontaneous hemoperitoneum from a ruptured superficial uterine vessel in third trimester of pregnancy. Bangladesh J obstet Gynecol. 2008;23(1):32-4.

4. Choobun T, Pinjaroen S, Getpook C. Spontaneous intra-abdominal bleeding during pregnancy. J Med Assoc Thai. 2006;89(7):1044-6.

5. Wu CY, Hwang JL, Lin YH, Hsieh BC, Seow KM, Huang LW. Spontaneous hemoperitoneum in pregnancy from a ruptured superficial uterine vessel. Taiwan J Obstet Gynecol. 2007;46(1):77-80 